\title{
Comparison of six response-elimination techniques following VR reinforcement training in humans*
}

\author{
JOHN W. PICKERING \\ Louisiana State University, Baton Rouge, Louisiana 70803 \\ and \\ JEFF S. TOPPING
Mississippi State University, Mississippi State, Mississippi 39762
}

\begin{abstract}
The present study employed humans in an examination of the relative response-eliminating effects of the following six procedures: Extinction training, omission training, response cost, omission training plus response cost, extinction training plus response cost, and omission training with a gradual introduction. Results indicated that all procedures eliminated responding significantly more effectively than did extinction training. In addition, omission training plus response cost, extinction training plus response cost, and omission training with a gradual introduction reduced responding significantly more effectively than did either omission training or response cost, which did not differ significantly from each other. Finally, omission training plus response cost and extinction training plus response cost decreased responding significantly more efficiently than did omission training with a gradual introduction, although they were not significantly different from each other.
\end{abstract}

Much research attention has concentrated on assessing the relative response-eliminating effects of omission training, in which $S$ is reinforced for omitting a previously reinforced response, and extinction training. In general, these studies (cf. Miller \& LeBlanc, 1972; Topping \& Larmi, 1973; Topping, Pickering, \& Jackson, 1971, 1972; Uhl \& Garcia, 1969; Uhl \& Sherman, 1971; Zeiler, 1971) have employed infrahuman Ss and have found that omission training is the more efficient technique, especially with regard to the durability of the response elimination.

Because of the paucity of data on the elimination of responding in humans, Johnson, McGlynn, and Topping (1973) recently employed college students in a comparison of four response elimination procedures. Their results indicated that response cost (punishment), omission training plus response cost, and omission training reduced responding significantly faster than did extinction training. Although the effects of response cost and omission training plus response cost did not differ significantly from each other, both procedures eliminated responding significantly more rapidly than did omission training.

The present experiment was designed to (a) replicate and extend portions of the Johnson et al (1973) study, as well as provide additional response elimination data on humans; (b) provide a more sensitive comparison of response cost and omission training plus response cost in

*Supported in part by National Science Foundation Institutional Grant for Science R200K-9100 to the junior author. Requests for reprints should be sent to Jeff S. Topping, P.O. Drawer PF, Mississippi State University, Mississippi State, Mississippi 39762 . order to determine if these two procedures have differential effects in the elimination of responding; and (c) assess the relative response-eliminating effects of two procedures not included in the Johnson et al study; these procedures are extinction training plus response cost and an omission training group, patterned after Topping, Larmi, \& Johnson (1972), in which the required duration of response omission is lengthened gradually, as opposed to when the final and maximum duration is employed from the beginning of omission training.

\section{METHOD}

Subjects

The Ss were 60 male and female undergraduate college students from Mississippi State University who participated in order to partially fulfill an introductory course requirement.

\section{Apparatus}

A $19 \frac{1}{2} \times 19 \frac{1}{2}$ in. vertical display panel with an attached $18 \times$ 18 in. horizontal platform was mounted on a table directly in front of the S. Two vertically arranged four-digit Lehigh Valley counters (Model 521-72) were mounted on the vertical panel. To the left of the top counter was a green stimulus light, and on the right was the label "positive." Located to the left of the bottom counter was a red stimulus light, and on the right of this counter was the label "negative." A standard telegraph key was mounted in the center of the horizontal panel. Experimental events and data recording were controlled by electromechanical programming equipment located in an adjacent room.

\section{Procedure \\ The experiment was conducted during one session for each $\mathrm{S}$ and consisted of three phases: (a) instructions, (b) VR} reinforcement training, and (c) response elimination. 
Table 1

Mean Transformed Response Rates During Response Elinination

\begin{tabular}{|c|c|c|c|c|c|c|c|c|c|c|c|}
\hline \multirow[b]{2}{*}{ Procedure } & \multirow{2}{*}{$\begin{array}{c}\text { VR } \\
\text { Response } \\
\text { Rate } \\
\text { (per min) }\end{array}$} & \multicolumn{10}{|c|}{ Intervals } \\
\hline & & 1 & 2 & 3 & 4 & 5 & 6 & 7 & 8 & 9 & 10 \\
\hline ET & 194.2 & .859 & .773 & .746 & .613 & .634 & .711 & .705 & .726 & .757 & .694 \\
\hline OT & 206.9 & .682 & .480 & .403 & .365 & .174 & .087 & .085 & .052 & .053 & .000 \\
\hline $\mathrm{RC}$ & 290.4 & .329 & .249 & .329 & .272 & .251 & .268 & .224 & .228 & .157 & .148 \\
\hline $\mathrm{OT}+\mathrm{RC}$ & 269.2 & .078 & .019 & .007 & .006 & .007 & .002 & .000 & .000 & .000 & .000 \\
\hline $\mathrm{ET}+\mathrm{RC}$ & 268.2 & .006 & .012 & .034 & .002 & .001 & .001 & .001 & .001 & .001 & .001 \\
\hline OT-grad & 277.3 & .655 & .504 & .209 & .144 & .048 & .033 & .002 & .000 & .000 & .000 \\
\hline
\end{tabular}

Instructions. Each $S$ appeared individually at a waiting area, from which he was taken to the experimental room and seated at a table. The following typewritten instructions were located on the table and were read by each $\mathrm{S}$ :

"The experiment you are about to participate in will offer you a unique opportunity to gain experimental credit hours over and above that given for participation in the experiment. The extra experimental credit will depend on your performance during the experiment. You may press the key, and if so, you may use either hand. Press the key only if you desire. A green light, located to the left of the top counter, will flash indicating you have earned ten (10) points. Flashes of the red light, located to the left of the bottom counter, indicate that one (1) point has been taken away. The counters in front of you will let you see your point totals at all times. The counter on top registers positive points and has the green light. The counter on the bottom shows negative points that will be subtracted from the top counter. This bottom "negative" counter has the red light beside it.

"Now we are about to begin. Keep in mind that the idea is to obtain as many net positive points as possible and that the points you accumulate are in some way related to the telegraph key. Remember you may press the key with either hand, but only if you desire to press it. The more net positive points you earn, the more extra experimental credit you will receive. The $\mathrm{E}$ will come in and tell you when the experiment is over and how many extra experimental hours you have earned. Any questions?"

In answering any questions, $E$ restated the instructions or whatever part of them was pertinent. In addition, $E$ verbally reminded $\mathrm{S}$ to try to earn as many net possible points as possible.

VR Reinforcement Training. During this phase, responding on the telegraph key was reinforced according to a VR 12 schedule. Reinforcement consisted of the green light flashing and the acquisition of 10 points as registered on the top ("positive") counter. VR training continued until S's response rate showed less than $20 \%$ interblock variability during four successive 30 -sec blocks.

Response Elimination. After the stabilization of responding, each $\mathrm{S}$ was exposed to a $15-\mathrm{min}$ period of response elimination, during which one of the following randomly assigned six procedures was in effect:

(1) Extinction Training (ET)-During ET, reinforcement no longer followed the previously reinforced keypress response, and $\mathrm{S}$ had no opportunity to obtain additional points after the VR 12 reinforcement training.

(2) Omission Training (OT)-In OT, a keypress postponed reinforcement for $10 \mathrm{sec}$, while omission of a keypress for $10 \mathrm{sec}$ produced reinforcement. By not responding, $S$ acquired reinforcement after each 10-sec interval [see Uhl \& Garcia (1969) for procedural specifications of omission training]

(3) Response Cost (RC)-During RC, one point was subtracted from S's point total following each keypress. This was represented by the bottom counter operating and the adjacent red light flashing. Reinforcement was still available during this procedure according to the VR 12 schedule [see Kazdin (1972) for procedural specifications].
(4) Omission Training Plus Response Cost (OT+RC)-In $\mathrm{OT}+\mathrm{RC}, \mathrm{S}$ lost a point contingent upon each keypress and delayed for $10 \mathrm{sec}$ the acquisition of reinforcement on the top counter. If no keypresses were emitted, reinforcement was delivered after each 10 -sec interval.

(5) Extinction Training Plus Response Cost $(E T+R C)$-During $\mathrm{ET}+\mathrm{RC}$, reinforcement was no longer available and each keypress resulted in the loss of one point from S's total. These negative points registered on the bottom counter simultaneously with the flashing of the red light.

(6) Omission Training-Gradual Introduction (OT-gradual)-In OT-gradual, a keypress initially postponed reinforcement for $4 \mathrm{sec}$, while omission of a keypress for $4 \mathrm{sec}$ produced reinforcement. These intervals were increased in 2 -sec steps until the final and maximum value of $10 \mathrm{sec}$ was reached. The criterion for increasing the interval duration was three or fewer responses in the course of five consecutive reinforcements.

\section{RESULTS}

The number of responses in each 30-sec interval was recorded throughout VR reinforcement and response elimination. During the response-elimination phase, S's response rate during each 90 -sec interval was transformed by treating it as a proportion of his stabilized response rate, i.e., mean of the last four $30-\mathrm{sec}$ period, at the conclusion of VR reinforcement training. Thus, a transformed value of 1.00 indicates responding at a rate equal to that observed at the termination of VR reinforcement training, and a value of 0.00 indicates complete cessation of the keypress response. The group mean transformed response rates observed during each 90 -sec interval of response elimination, as well as the group mean stabilized response rate observed at the conclusion of VR reinforcement training, are presented in Table 1.

A 6 (groups) by 10 (intervals) repeated-measures analysis of variance (Winer, 1962) was performed on the transformed response-elimination data summarized in Table 1 . The results of this analysis yielded significant main effects for groups $(\mathrm{F}=18.6, \mathrm{df}=5 / 42, \mathrm{p}<.01)$ and intervals $(\mathrm{F}=21.8, \mathrm{df}=9 / 378, \mathrm{p}<.01)$, as well as a significant Groups by Intervals interaction $(\mathrm{F}=4.6, \mathrm{df}=$ $45 / 378, p<.01)$.

Results from tests of simple main effects suggested that all procedures eliminated responding significantly $(\mathrm{p}<.01)$ more efficiently than did ET. Also, OT $+\mathrm{RC}$, ET $+R C$, and OT-gradual reduced responding significantly $(p<.01)$ more effectively than did OT and $\mathrm{RC}$, which did not differ significantly from each other. 
Furthermore, OT $+\mathrm{RC}$ and $\mathrm{ET}+\mathrm{RC}$ decreased responding significantly $(p<.01)$ more efficiently than did OT-gradual, although they were not significantly different from each other.

Duncan's tests (Kirk, 1968) were employed to identify the sources of the significant interaction effect. These tests revealed that the effects of $\mathrm{RC}, \mathrm{OT}+\mathrm{RC}$, and $\mathrm{ET}+\mathrm{RC}$ differed significantly $(\mathrm{p}<.01)$ from those of OT, OT-gradual, and ET during the first interval of response elimination. Among the effects of the former and latter three procedures, no significant differences were observed at this time. Over Intervals $2-4$, the effects of OT-gradual and then OT became grouped with those of the RC procedures. For Intervals 5-10, only the effects of ET differed significantly $(p<.01)$ from those of each of the remaining five procedures, which did not differ significantly from each other.

\section{DISCUSSION}

The results of the present study are generally in accord with previous data concerning response-elimination techniques. For instance, the present finding that OT is a more efficient method of eliminating responding than ET supports the conclusions of Johnson et al (1973), Miller and LeBlanc (1972), Topping and Larmi (1973), Topping, Pickering, and Jackson (1971, 1972), and Zeiler (1971).

The finding that $\mathrm{OT}+\mathrm{RC}$ reduced responding more effectively than OT replicates the data of Johnson et al (1973), and parallels that of Uhl and Sherman (1971), who concluded that shock punishment plus OT decreased responding more efficiently than did OT alone. Apparently the RC contingency employed in the present experiment and in the Johnson et al study affected responding in the same manner as did the shock punishment utilized by Uhl and Sherman, i.e., it quickly suppressed responding and allowed the OT contingencies to take effect much sooner than would occur under nonpunitive circumstances.

Positive reinforcement contingencies in the RC situations were altered in the present experiment from those of the Johnson et al (1973) study in order to provide a more sensitive measure of any differences which might exist between the effects of RC and OT+RC. While both studies used the loss of one point per response as the response cost, reinforcement for Johnson et al consisted of 1 point administered on a VR 8 schedule, whereas the present investigation offered 10 points per reinforcement according to a VR 12 schedule. It was hypothesized that the failure to obtain a significant difference between the effects of $\mathrm{RC}$ and $\mathrm{OT}+\mathrm{RC}$ in the Johnson et al experiment was possibly due to the extreme aversiveness of the punishment, whereby responding was immediately suppressed under any contingency of RC. It was predicted that in the present experiment punishment would not prove so aversive and responding under $\mathrm{RC}$ would continue at a substantial rate to allow comparisons between conditions involving RC. The findings of the present experiment support this latter contention in that OT+RC was significantly more effective in eliminating responding than $\mathrm{RC}$.

The effects of the OT+RC procedure did not, however, differ significantly from the effects of ET+RC. This finding is in. agreement with analogous results on the effects of combinations of shock punishment and OT or ET (Uhl \& Sherman, 1971). It appears that these two procedures are equally effective in reducing responding. It is possible that $\mathrm{OT}+\mathrm{RC}$ might be the preferred method however, as it does offer a means of positive control, and contrasts with the strictly negative contingency of ET+RC.
The present finding that OT-gradual was significantly more effective in eliminating responding than OT supports an earlier finding obtained with pigeons (Topping, Larmi, \& Johnson, 1972). A possible explanation for this superiority of the OT-gradual procedure lies in the availability of early reinforcement for nonresponding behavior. In OT, $S$ is initially exposed to pure extinction training until he withholds responding long enough to obtain his first reinforcement. His behavior then falls under the control of two different contingencies operating concurrently: (1) extinction of the to-be-eliminated response, and (2) reinforcement of any other behavior. It seems reasonable to assume that the OT-gradual procedure provides for relatively early "recognition" of these two contingencies and, thus, for rapid modification of S's original behavior.

A notable difference between the present study and that of Johnson et al (1973) was the terminal rate of responding during response acquisition. The average stabilized response rate reported by the earlier study was 61.7 responses per minute, whereas the average response rate in the present experiment was 251 responses per minute. It is possible that the higher rate of responding in the present study was due to its larger magnitude of reinforcement (10 points per reinforcement as opposed to 1 point in the earlier study). Another possibility lies in the pretreatment instructions. The written instructions were virtually identical in both studies except for the reference to number of points per reinforcement. However, in the present study, following S's reading of the instructions, E verbally reminded $S$ to attempt to accumulate as many net positive points as possible. It is quite possible that such a verbal instruction by $\mathrm{E}$ was effective in increasing response rate during acquisition, although the present authors are still somewhat uncertain as to the interpretation of the large difference in response rate between the two studies.

\section{REFERENCES}

Johnson, D. L., McGlynn, F. D., \& Topping, J. S. The relative efficiency of four response-elimination techniques following variable-ratio reinforcement training. Psychological Record, $1973,23,203-208$.

Kazdin, A. Response cost: The removal of conditioned reinforcers for therapeutic change. Behavior Therapy, 1972, 3, 533-546.

Kirk, R. E. Experimental design: Procedures for the behavioral sciences. Belmont: Wadsworth, 1968.

Miller, D. N., \& LeBlanc, J. M. Response decrement and resumption: A comparison of responding during and after differential reinforcement of other behavior. Paper presented at the meeting of the American Psychological Association, Honolulu, 1972.

Topping, J. S., \& Larmi, O. K. Response elimination effectiveness of omission and two extinction training procedures. Psychological Record, 1973, 23, 197-202. Topping, J. S., Larmi, O. K., \& Johnson, D. L. Omission Science, 1972, 28, 279-280.

Topping, J. S., Pickering, J. W., \& Jackson, J. A. The differential effects of omission and extinction following DRL pretraining. Psychonomic Science, 1971, 24, 137-138.

Topping, J. S., Pickering, J. W., \& Jackson, J. A. Comparison of omission and extinction following FR reinforcement training. Psychological Record, 1972, 22, 221-224.

Uhl, C. N., \& Garcia, E. E. Comparison of omission with extinction in response elimination in rats. Journal of Comparative \& Physiological Psychology, 1969, 69, 554-562.

Uhl, C. N., \& Sherman, W. O. Comparison of combinations of omission, punishment, and extinction methods in response elimination in rats. Journal of Comparative \& Physiological Psychology, 1971, 74, 59-65.

Winer, B. J. Statistical principles in experimental design. New York: McGraw-Hill, 1962.

Zeiler, M. Eliminating behavior with reinforcement. Journal of the Experimental Analy sis of Behavior, 1971, 16, 401-405.

(Received for publication January 24, 1974.) 